\title{
CONCEPTUAL ADSORPTION SYSTEM OF COOLING AND HEATING SUPPLIED BY SOLAR ENERGY
}

\author{
Michał Turski*, Robert Sekret \\ Czestochowa University of Technology , Faculty of Infrastructure and Environment, \\ 60A Brzeznicka St., 42-200 Czestochowa, Poland
}

This paper presents the possibility of reducing the demand for nonrenewable primary energy for buildings using a new conceptual adsorption system of cooling and heating supplied by solar energy. Moreover, the aim of this study is to shorten the payback time of investment in the standard adsorption cooling system through its integration with the heating system. Research has been carried out for an energy-efficient medium-sized single-family building with a floor area of $140 \mathrm{~m}^{2}$ and a heat load of $4.2 \mathrm{~kW}$ and cold load of $4.41 \mathrm{~kW}$. It has been shown that the use of an adsorption system of cooling and heating supplied by solar energy decreased the demand for nonrenewable primary energy by about $66 \%$ compared to the standard building that meets the current requirements.

Keywords: solar cooling, solar heating, solar energy, adsorption chiller, adsorption ice water generator

\section{INTRODUCTION}

Current research on radical reduction of energy consumption in the building and installation sector necessitates intensive thermal modernization of existing buildings and development of extremely low power consumption buildings technology. It should be noted that, on the one hand, there is a significant reduction in the heat loss because of heat transfer and air infiltration through the building enclosure (reduction of primary energy demand in the heating season). On the other hand, high tightness of the building enclosure necessitates cooling the interior of the building during the summertime (increase in primary energy demand). Current research is aiming at the implementation of low-energy solutions in building and installation systems in the form of decentralised energy supply systems (Cholewa et al., 2011), or central heating and cooling systems based on renewable energy sources (Eshraghi et al., 2014). The problems of energy consumption of the heating system and hot water heating system have been largely solved (Carutasiu et al., 2016; Chou et al., 2016; Gargari et al., 2016; Palm and Reindl, 2016; Wojdyga, 2009).

One of the current trends of decreasing the demand for nonrenewable primary energy for cooling in the summer is the use of cooling and air conditioning systems supplied by solar energy, among which adsorption cooling systems have some of the lowest temperatures of the heating medium $\left(60{ }^{\circ} \mathrm{C}\right)$, reaching relatively good coefficient of performance values-COP approximately 0.65 (Hassan and Mohamad, 2012; La et al., 2011; Li et al., 2013; Sarbu and Sebarchievici, 2013). An additional advantage of the use of chillers supplied by solar energy is the occurrence of the maximum cooling demand of the building and the maximum intensity of solar radiation at the same time, both during the year and day. In recent years, much research has been conducted on the use and operation of adsorption 
cooling systems. Research on the grains of the sorbent configuration and their granulation was carried out by (Aristov et al., 2012a), and research on the use of adsorbent-adsorbate pair was carried out by (Askalny et al., 2013). The adsorption cooling system using zeolite-water pair has also been examined by (Solmus et al., 2011), finding application in car air conditioning (Vasta et al., 2012). The degree of adsorption of gases using zeolites for capturing carbon dioxide from flue gases for low parameters of adsorption process was investigated by (Wawrzyńczak and Nowak, 2009). A pair of activated carbonwater has been examined by ( $\mathrm{Lu}$ et al., 2013a; Tso et al., 2012), and a pair of activated carbonmethanol has been examined by (Schicktanz et al., 2012), using other refrigerants having little effect on the greenhouse effect (Jribi et al., 2013), and selective water sorbents (Freni et al., 2012). A silica gelwater pair has been studied by (Lu et al., 2013b; Rezk et al., 2012). Research on increasing the efficiency of adsorption chillers and adsorption cooling systems has been conducted by (Sapienza et al., 2012; Zhang et al., 2013), using waste heat (Mayt et al., 2013; Tso et al., 2012). The effect of duration of adsorption/desorption process on the cooling efficiency of the adsorption chiller is carried out by (Aristov et al., 2012b; Szyc and Nowak, 2014). Studies on thermodynamic analysis have been carried out by (Hassan et al., 2012).

Despite continuing research, it is concluded that the construction and the use of low capacity adsorption cooling systems supplied by solar energy, in Poland, are not yet a known issue. So far, the basic guidelines have been developed for the construction of low capacity adsorption chiller for Polish climatic conditions in the context of the doctoral dissertation "Theoretical and experimental research on adsorptive systems of the solar air-conditioning" with presentation of some results (Sekret and Turski, 2012). In the course of a critical analysis of the available literature and on the basis of own research, an adsorption chiller and an adsorption cooling system supplied by solar energy, ensuring thermal comfort in the room, were built.

Based on the review of the literature and the current distributors' offer of adsorption chillers and other elements of the system (SorTechAG, 2015; Powerauditing, 2015), it is found that the sorption cooling systems are still an expensive technology. This results in a long payback time of investment (i.e., more than 25 years), which is a serious problem posed by such solutions.

Increase in operating costs is caused by the irreversibility of thermal processes. To reduce the thermodynamic imperfections of heat transfer processes, minimising the losses of exergy is necessary. On the other hand, to achieve almost reversible processes (using small gradients of physical quantities), the size of heating exchangers must be significantly increased. Therefore, it is necessary to allow exergy losses to reduce investment costs. To achieve a compromise between aspects of energy efficiency and operating costs, exergetic loss that has no economic justification should be eliminated. In general, the practical reduction of thermodynamic imperfection of thermal processes is advantageous to implement processes that can produce more than one useful effect (Cholewa et al., 2013; Szargut, 2010; Szargut and Stanek, 2010).

Furthermore, studies of adsorption cooling systems are mainly related to increasing the efficiency of adsorption chillers. From an energetic and economic point of view, the solution for the entire system is important-not just one element, which is a source of cold. It should be guided by the principles of the impact of proposed energy changes on exergy losses elsewhere in the system, so that a reduction in the loss of exergy of one element does not increase any other loss occurring simultaneously.

The Coolsun study (Facao et al., 2014) — performed within the Seventh Framework Program — took into consideration the energy and economic analysis of the heating, cooling and hot water system for a building with an area of $125 \mathrm{~m}^{2}$ (France near Bordeaux.) Studies have shown that the Coolsun system can operate effectively in Central Europe, covering 100\% of the demand for heating and cooling. In contrast, a better balance is achieved for larger installations, so the Coolsun system is dedicated to countries with high cost of energy. Therefore, based on the review of the literature and our studies (Secret and Turski, 2012), a solution of conceptual adsorption system of cooling and heating supplied 
by solar energy dedicated to single-family buildings was proposed. The main purpose of this solution is to reduce the demand for nonrenewable primary energy, while reducing the payback time of costs in relation to the adsorption cooling system in Polish climatic conditions.

\section{A CONCEPT FOR THE ADSORPTION SYSTEM OF COOLING AND HEATING SUPPLIED BY SOLAR ENERGY}

\subsection{Description of the object}

At first to compare the results of using the proposed conceptual adsorption system of cooling and heating supplied by solar energy, a standard medium-sized single-family building with a floor area of $140 \mathrm{~m}^{2}$ that meets the current requirements has been designed. The object has been characterised as a single-family (four people) building with an attic and a double garage within the body of the building, without a basement. The current monthly percentage demand for nonrenewable primary energy for the standard building in Poland (energy demand for heating of $103 \mathrm{kWh} /\left(\mathrm{m}^{2}\right.$ year)) is shown in Fig. 1. A value of $100 \%$ was defined as maximum demand for nonrenewable primary energy. Monthly demand may vary due to the different nonrenewable primary energy demand. The maximum demand for nonrenewable primary energy occurs in the coldest month (January) due to the heating and in the warmest months (July, August) due to cooling.

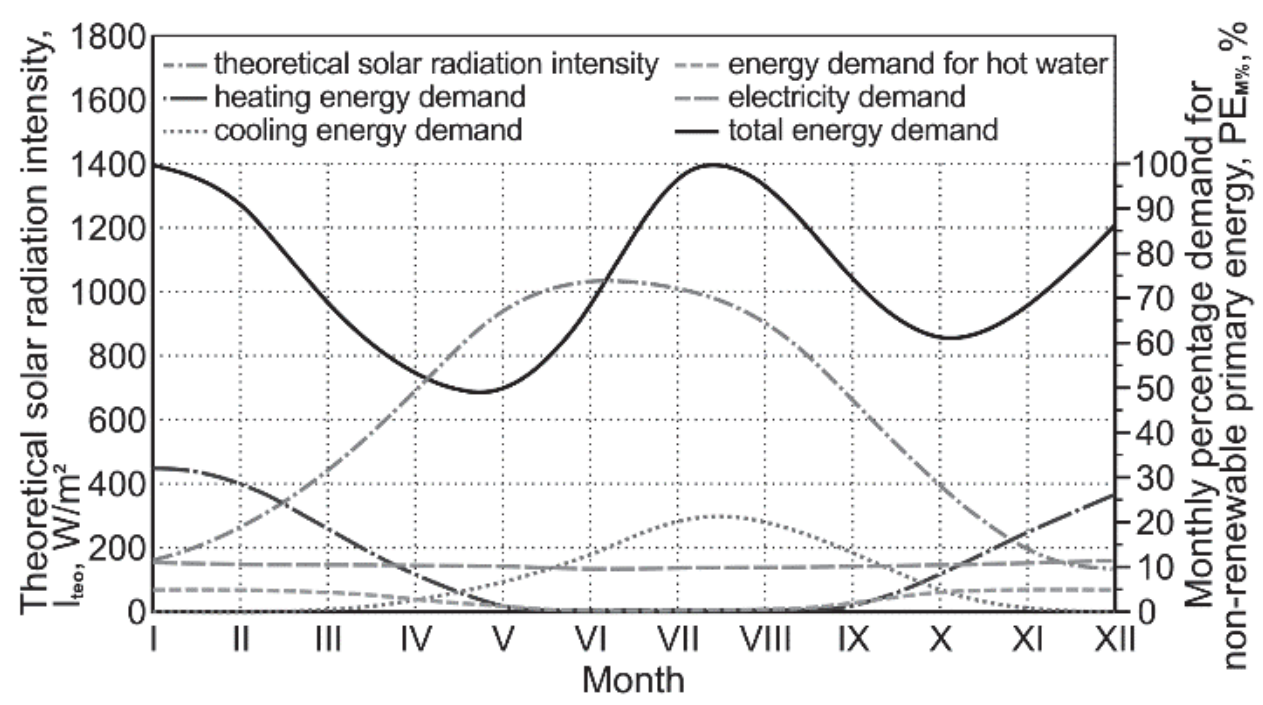

Fig. 1. Theoretical solar radiation intensity and monthly percentage demand for nonrenewable primary energy for the standard building (area $140 \mathrm{~m}^{2}$ ) in Poland

The total nonrenewable primary energy demand is the sum of the individual values of the energy demand for heat, cold, electricity, and hot water enlarged by coefficients of effort of nonrenewable primary energy to produce and supply energy carrier. Coefficients of effort were as follows: for heat (central heating system with radiators supplied by a gas boiler) 1.1, for cold (compressor cooling unit) 3.0, and for hot water (condenser hot water tank) 3.0. This is due to the generation of cold and hot water by means of electricity.

To conduct the process of associated production of more than one useful effect to reduce thermodynamic imperfections of the heat transfer processes while achieving better economic effect, it is necessary to integrate the heating and cooling system and reduce the operating parameters of the heating system. Therefore, the analysed building has been made using the energy-efficient technology (energy demand for heating of $30 \mathrm{kWh} /\left(\mathrm{m}^{2}\right.$ year $)$ ), in contrast to a standard building in Poland as 
described above, and the adsorption, air system of cooling, and heating supplied by solar energy have been used.

Because of heat income statement, the heat and cold loads of the energy-efficient single-family building with area of $140 \mathrm{~m}^{2}$ have been defined. The heat load was $4.2 \mathrm{~kW}$ and the cold load was $4.41 \mathrm{~kW}$.

In the winter, the maximum temperature for heating air was at the level of $35^{\circ} \mathrm{C}$, the average internal temperature was about $20^{\circ} \mathrm{C}$, and a minimum external temperature was at the level of $-20^{\circ} \mathrm{C}$, and heat recovery efficiency was $80 \%$. For those conditions, the maximum value of the ventilation air flow relative to the floor area of $1 \mathrm{~m}^{2}$ was $6.56 \mathrm{~m}^{3} /\left(\mathrm{h} \mathrm{m}^{2}\right)$. Therefore, the total airflow was $918 \mathrm{~m}^{3} / \mathrm{h}$.

In the summer, in accordance with the thermal comfort conditions, assuming the maximum value of the outlet air temperature at the level of $32^{\circ} \mathrm{C}$ and the inlet air temperature at the level of $25{ }^{\circ} \mathrm{C}$, the maximum temperature difference between the outlet and inlet air was equal to $7 \mathrm{~K}$ (Abreu-Harbich et al., 2014; Jazizadeh et al., 2014). The ventilation airflow relative to the floor area of $1 \mathrm{~m}^{2}$ was $11.15 \mathrm{~m}^{3} /\left(\mathrm{h} \mathrm{m}^{2}\right)$. The total airflow was $1561.62 \mathrm{~m}^{3} / \mathrm{h}$.

\subsection{Operating parameters}

In a traditional building, the greatest power consumption results from heating. Low-energy and passive buildings construction is characterised by an extreme decrease in the demand for heating purposes. During the summer, necessity to ensure thermal comfort and minimum hygiene conditions (mostly reduce the $\mathrm{CO}_{2}$ concentration) causes an increase in energy demand for cooling purposes at a comparable or higher level than for heating purposes. Therefore, $\mathrm{AC}$ is the first unit designed in the adsorption system of cooling and heating supplied by solar energy. Based on the cold load, an AC cooling capacity of $7.8 \mathrm{~kW}$ was selected. The unitary value of AC cooling capacity was $55.71 \mathrm{~W} / \mathrm{m}^{2}$, and the unitary value of AC cooling capacity per user was $13.93 \mathrm{~W} /\left(\mathrm{m}^{2}\right.$ user $)$, which gives $1.95 \mathrm{~kW}$ cooling capacity to a single user.

Other parameters of the adsorption cooling system depend on the specifics of AC. Based on our previous research (Sekret and Turski, 2012), for a cooling capacity of $7.8 \mathrm{~kW}$, it is necessary to supply a heating power of $12.91 \mathrm{~kW}$ and heating medium temperatures in the range of $60-95{ }^{\circ} \mathrm{C}$ and a thermal power of heat rejection at the level of $20.71 \mathrm{~kW}$ and condenser cooling medium temperatures in the range of $24-37^{\circ} \mathrm{C}$. Heat rejection is understood as the heat output from the cooled building, and the heat supplied to the AC. Based on these values, parameters of the heating medium circuit $\left(74^{\circ} \mathrm{C}\right.$ supply, $67^{\circ} \mathrm{C}$ return) and a condenser cooling medium circuit $\left(29^{\circ} \mathrm{C}\right.$ supply, $34^{\circ} \mathrm{C}$ return) for which the analysis was carried out were determined experimentally. Temperatures of the cold-water circuit have also been experimentally determined (supply $18^{\circ} \mathrm{C}$ and return $12^{\circ} \mathrm{C}$ ).

The value of solar collector area needed to produce $1 \mathrm{~kW}$ of AC cooling power was $3.73 \mathrm{~m}^{2}$ for the size of the cooling and heating system. The solar collector area to power the entire system was $29.2 \mathrm{~m}^{2}$; therefore, it was necessary to use 11 solar collectors.

For heating purposes, the system works as an adsorption heat pump with a lower heat source in the form of solar collectors. When a large solar collector area is used in the summer for cooling, and the pressure working conditions of AC ranged from 500 to $2000 \mathrm{~Pa}$, the working medium needs a minimum energy (heat) to evaporate passing the heat to the adsorber. For further desorption process, a gas-jet was used to heat the surface of the adsorber. Steam of working medium transfers heat to the condenser, where it is collected by the system of air heating. 


\section{A NEW CONCEPTUAL ADSORPTION SYSTEM OF COOLING AND HEATING SUPPLIED BY SOLAR ENERGY}

\subsection{Test stand}

In our previous studies, a test stand has been built. It consists of the following: a generation module, an accumulation module, a transmission module, and an energy usage module. In the present studies, the test stand has been enhanced by the heating system. Based on the research carried out on a test stand, a conceptual ASCH was designed for the low-energy building (area $140 \mathrm{~m}^{2}$ ) in Poland. Extensive test stand is presented in Fig. 2.

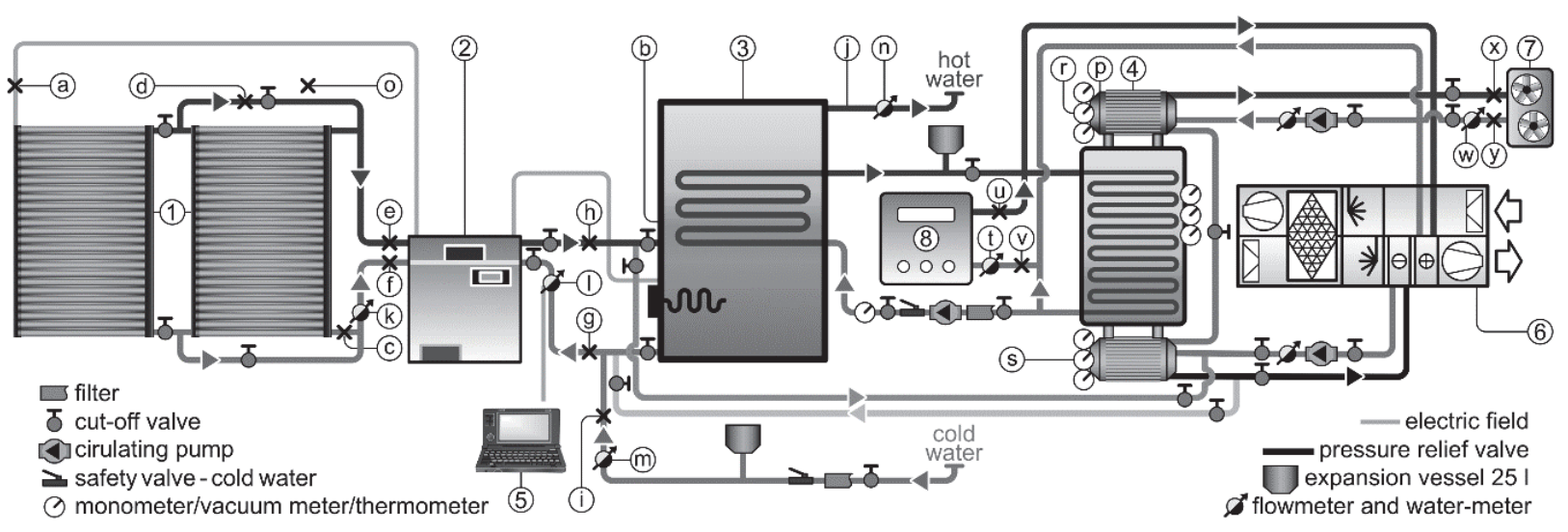

Fig. 2. Conceptual adsorption system of cooling and heating test stand

The generation module was responsible for creating heat and cold. It included a set of solar collectors (1) with solar module (2), an additional source of heat - gas boiler (8), and an AC (4). The accumulation module included an accumulator of heat (3). It was used to define and configure possible levels of cooling and heating power in the created conditions. The next set of modules was used for transmission and utilization - external cooler (7) and air handling unit (6). It consisted of transmissionand-measurement fixtures and elements necessary for division and distribution of cold and heat in the room. A computer with a measurement card (5) was used to read and collect data.

\subsection{Research methodology}

Our earlier studies (Sekret and Turski, 2012) were related to ensuring thermal comfort conditions in a room of $40 \mathrm{~m}^{3}$ in volume. For this purpose, an adsorption cooling system supplied by flat-plate solar collectors was used. It has been shown that it is possible to operate the AC in the climatic conditions in a region of Czestochowa (Poland). As a result, it turned out that COP for the AC was 0.27, and the real global efficiency of the entire system was 0.23 .

According to the conclusions and assumptions of the previous study, steps were taken to increase the efficiency of $\mathrm{AC}$, in order to improve the coefficient of performance COP, thereby increasing the profitability of the investment. The next step that takes into account the increase in the efficiency of the entire adsorption cooling system, while reducing the demand for nonrenewable primary energy and increasing the profitability of the investment, was to analyse the working conditions of the new conceptual adsorption integrated system of cooling and heating.

To determine the temperature of the heating medium of solar circuit for solar collectors neosol 250, meteorological data typical for Polish climatic conditions were used. Moreover, solar collectors have been tested in real conditions. For the purposes of the experiment, the temperature of the heating 
medium of solar circuit was simulated using a gas boiler in summertime conditions and an electrical heater in wintertime conditions.

To the study, flat plate solar collectors neosol 250 have been used. However, to the supply of ASCH, both flat plate solar collectors, as well as vacuum tube solar collectors, can be used. The required amount of heat to be delivered to the system and the range of temperatures of heating medium is important.

Moreover, for the purposes of the experiment in wintertime conditions, the external cooler works as a simulator of central heating heat consumption. In the normal operation of $\mathrm{ASCH}$, heating takes place through air handling unit.

To determine the economic and ecological effects of the use of the ASCH in energy-efficient building, first it is necessary to designate the characteristics of the system, which would allow for the maintenance of conditions of thermal comfort for both the summer and winter. The effect of designation of the characteristics was to determine the system COP for cooling and heating processes. The most important elements affecting the operation of the system (also COP) are the temperatures of heating medium of solar circuit. Therefore, the solar circuit temperatures were simulated in the range of 65-85 ${ }^{\circ} \mathrm{C}$ (i.e., $65{ }^{\circ} \mathrm{C}, 70{ }^{\circ} \mathrm{C}, 72^{\circ} \mathrm{C}, 73{ }^{\circ} \mathrm{C}, 74{ }^{\circ} \mathrm{C}, 75^{\circ} \mathrm{C}, 76^{\circ} \mathrm{C}, 80{ }^{\circ} \mathrm{C}, 85^{\circ} \mathrm{C}$ ) for the summer period. Later, the same has been done for the winter period with temperature values of $26{ }^{\circ} \mathrm{C}, 28{ }^{\circ} \mathrm{C}$, and $30{ }^{\circ} \mathrm{C}$.

The initial temperature of the working medium in the evaporator was fixed at $18{ }^{\circ} \mathrm{C}$ for operation in summertime conditions, and for working in wintertime conditions, it was fixed at $24{ }^{\circ} \mathrm{C}$. According to (Jribi et al., 2013), the adsorption chiller can operate effectively when the time of adsorption and desorption (regeneration process) balance with each other. Therefore, the optimal periods of time 7.5/7.5 min for cooling and 7.0/7.0 min for heating were used in the experiment. By the assumptions of previous operating parameters of $\mathrm{ASCH}, 36$ measurements were carried out, 3 repetitions at each temperature of the reading of data every minute.

\section{ANALYSIS OF THE RESULTS}

Based on the analysis of new conceptual adsorption system of cooling and heating supplied by solar collectors, the parameters are described in Table 1.

The refrigerating efficiency coefficient for ASCH was determined. The dependences of the ASCH supplied by solar energy coefficient of performance as a function of time are presented in Fig. 3 for cooling and in Fig. 4 for heating. The data refer to the duration of the cooling and heating process equal to $60 \mathrm{~min}$, taking into account the optimal time of sorption. It is assumed that each cooling process is preceded by a regeneration process with heating medium temperatures ranging from $60{ }^{\circ} \mathrm{C}$ to $95{ }^{\circ} \mathrm{C}$. Some of the representative results for cooling process are shown for temperatures of heating medium: $65^{\circ} \mathrm{C}, 74^{\circ} \mathrm{C}$, and $80^{\circ} \mathrm{C}$. In the heating process, the results were presented, respectively, for temperatures of the lower heat source: $26^{\circ} \mathrm{C}, 28^{\circ} \mathrm{C}$, and $30^{\circ} \mathrm{C}$.

In the cooling process after the regeneration with heating medium temperatures of $65^{\circ} \mathrm{C}, 74^{\circ} \mathrm{C}$, and $80^{\circ} \mathrm{C}$ and at an initial evaporator temperature $18^{\circ} \mathrm{C}$, the maximum cooling capacity values were, respectively, $0.56,0.59$ and 0.5 . On this basis, it is concluded that the optimum regeneration temperature is $74^{\circ} \mathrm{C}$.

In the heating process for measurements of the temperatures of medium supplying lower heat source $26^{\circ} \mathrm{C}, 28^{\circ} \mathrm{C}$, and $30^{\circ} \mathrm{C}$ and at an initial evaporator temperature $12^{\circ} \mathrm{C}$, the maximum heating capacity 
values were, respectively, $1.5,1.6$, and 1.73. It can therefore be concluded that greater heating efficiency can be obtained at higher evaporator temperature.

Table 1. Parameters of conceptual adsorption system of cooling and heating.

\begin{tabular}{|c|c|c|c|c|}
\hline No & \multicolumn{2}{|c|}{ Description } & Value & Unit \\
\hline 1. & \multicolumn{2}{|l|}{ Cooling capacity of ASCH } & 7.8 & $\mathrm{~kW}$ \\
\hline 2. & \multicolumn{2}{|c|}{ Unitary value of ASCH cooling capacity } & 55.71 & $\mathrm{~W} / \mathrm{m}^{2}$ \\
\hline 3. & \multicolumn{2}{|c|}{ Unitary value of ASCH cooling capacity per user } & 13.93 & $\mathrm{~W} /\left(\mathrm{m}^{2}\right.$ user $)$ \\
\hline 4. & \multicolumn{2}{|l|}{ Cooling capacity to a single user } & 1.95 & $\mathrm{~kW}$ \\
\hline 5. & \multicolumn{2}{|l|}{ Heating capacity of ASCH } & 4.2 & $\mathrm{~kW}$ \\
\hline 6. & \multicolumn{2}{|c|}{ Unitary value of ASCH heating capacity } & 30 & $\mathrm{~W} / \mathrm{m}^{2}$ \\
\hline 7. & \multicolumn{2}{|c|}{ Unitary value of ASCH heating capacity per user } & 7.5 & $\mathrm{~W} /\left(\mathrm{m}^{2}\right.$ user $)$ \\
\hline 8. & \multicolumn{2}{|c|}{ Heating capacity to a single user } & 1.05 & $\mathrm{~kW}$ \\
\hline \multirow{2}{*}{9.} & \multirow{2}{*}{$\begin{array}{l}\text { Operating temperatures of the } \\
\text { heating medium circuit }\end{array}$} & summer; supply/return & $74 / 67$ & ${ }^{\circ} \mathrm{C}$ \\
\hline & & winter; supply/return & $67 / 67$ & ${ }^{\circ} \mathrm{C}$ \\
\hline \multirow{2}{*}{10.} & \multirow{2}{*}{$\begin{array}{l}\text { Operating temperature of the } \\
\text { condenser medium circuit }\end{array}$} & summer; supply/return & $29 / 34$ & ${ }^{\circ} \mathrm{C}$ \\
\hline & & winter; supply/return & $45 / 40$ & ${ }^{\circ} \mathrm{C}$ \\
\hline \multirow{2}{*}{11.} & \multirow{2}{*}{$\begin{array}{l}\text { Operating temperature of the } \\
\text { evaporator medium circuit }\end{array}$} & summer; supply/return & 18-gru & ${ }^{\circ} \mathrm{C}$ \\
\hline & & winter; supply/return & $30 / 27$ & ${ }^{\circ} \mathrm{C}$ \\
\hline 12. & \multicolumn{2}{|c|}{ Mass flow rate of the evaporator (cold water) } & 0.31 & $\mathrm{~kg} / \mathrm{s}$ \\
\hline 13. & \multicolumn{2}{|c|}{ Mass flow rate of the condenser (cooling medium) } & 0.99 & $\mathrm{~kg} / \mathrm{s}$ \\
\hline 14. & \multicolumn{2}{|c|}{ Mass flow rate of the adsorber (heating medium) } & 0.44 & $\mathrm{~kg} / \mathrm{s}$ \\
\hline 15. & \multicolumn{2}{|c|}{ Solar collectors area to power the entire system } & 29.2 (11 coll.) & $\mathrm{m}^{2}$ \\
\hline 16. & \multicolumn{2}{|c|}{ Pressure of intensive evaporation at temperature } & $2058 / 18$ & $\mathrm{~Pa} /{ }^{\circ} \mathrm{C}$ \\
\hline 17. & \multicolumn{2}{|c|}{ Minimum amount of working medium to the evap. proc. } & $14.27 \times 10^{-4}$ & $\mathrm{~m}^{3}$ \\
\hline 18. & \multicolumn{2}{|l|}{ Amount of adsorbent } & 40.8 & $\mathrm{~kg}$ \\
\hline 19. & \multicolumn{2}{|c|}{ Heat exchangers area evaporator/condenser/adsorber } & $1.33 / 3.52 / 2.19$ & $\mathrm{~m}^{2}$ \\
\hline 20. & \multicolumn{2}{|l|}{ Volume of heat/cold storage } & $1.84 / 0.43$ & $\mathrm{~m}^{3}$ \\
\hline
\end{tabular}

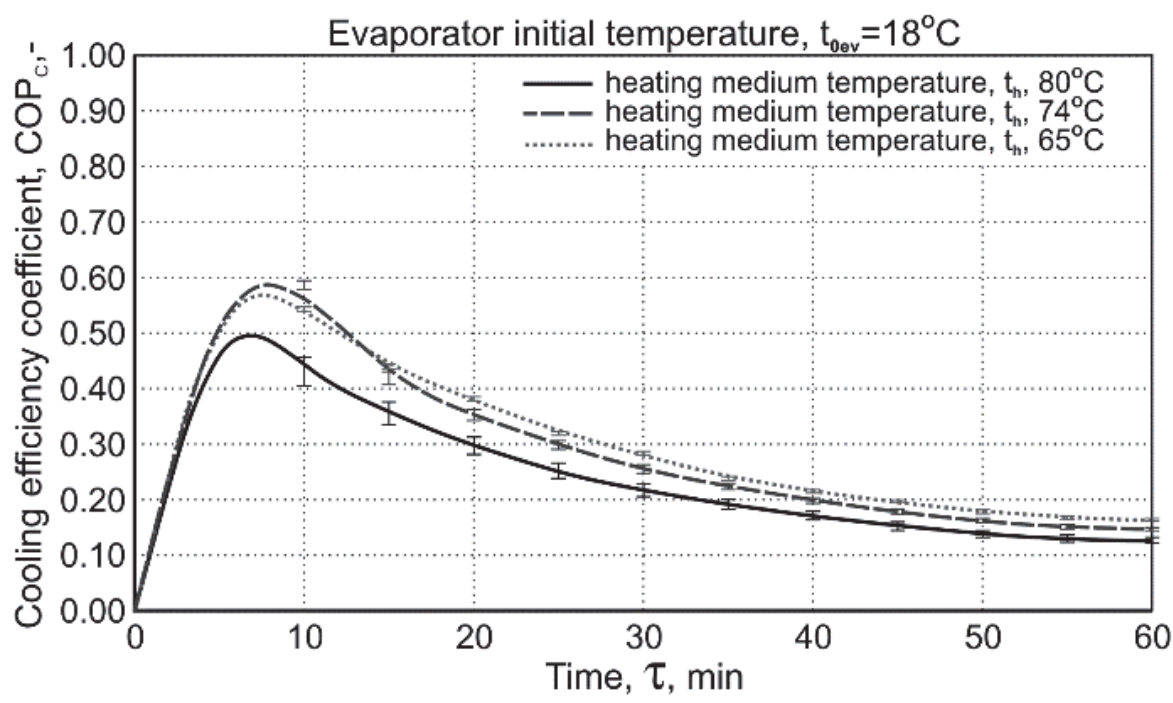

Fig. 3. Dependence of the ASCH cooling efficiency coefficient as a function of time 


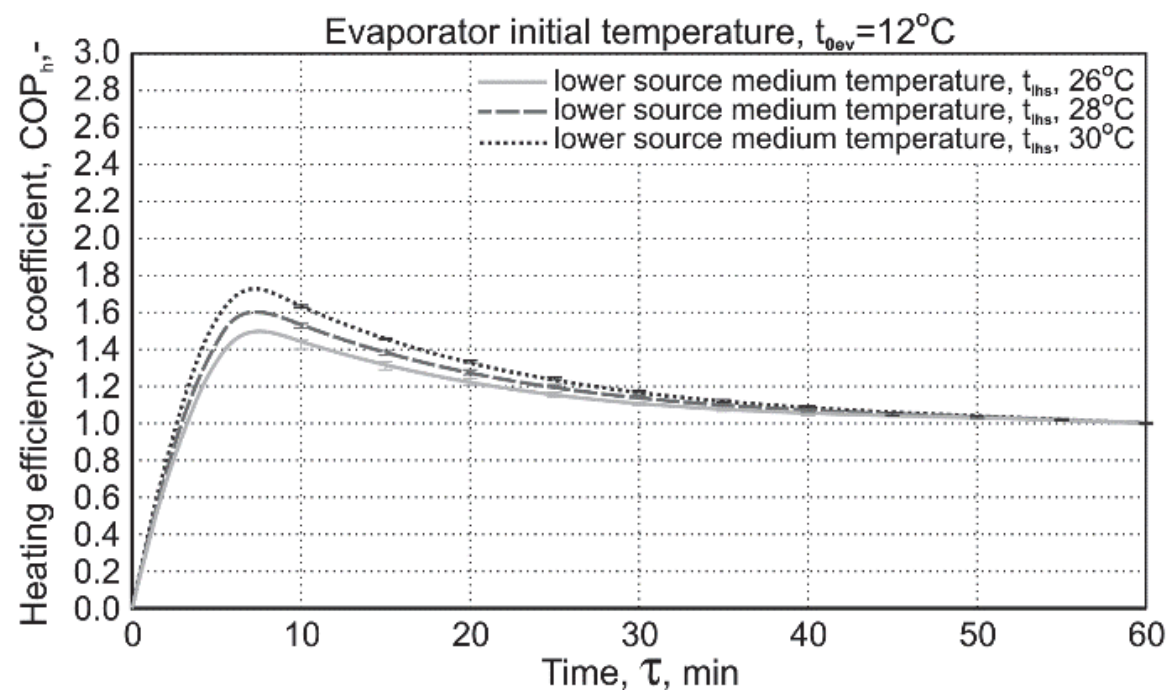

Fig. 4. Dependence of the ASCH heating efficiency coefficient as a function of time

Furthermore, it was confirmed that the concept assumptions for the cooling process of cold water circuit temperatures $18{ }^{\circ} \mathrm{C}$ for supply and $12^{\circ} \mathrm{C}$ for return, as well as the heating medium circuit temperatures $74{ }^{\circ} \mathrm{C}$ for supply and $67^{\circ} \mathrm{C}$ for return and for heating process: for lower heat source circuit temperatures $30^{\circ} \mathrm{C}$ supply, $27^{\circ} \mathrm{C}$ return as well as the air heating operating temperatures $35^{\circ} \mathrm{C}$ supply, $26^{\circ} \mathrm{C}$ return allow to achieve for entire ASCH the coefficient of performance COP value of 1.02 .

\section{ECONOMIC AND ECOLOGICAL EFFECTS OF ADSORPTION SYSTEM OF COOLING AND HEATING SUPPLIED BY SOLAR ENERGY}

Problems caused by the variability of solar radiation intensity are avoided by using solar energy for cooling purposes. The maximum cooling demand of the building is received at maximum solar radiation intensity. Therefore, the use of adsorption cooling systems supplied by solar collectors increase the potential of solar energy utilization, by reducing significantly the demand for nonrenewable primary energy for cooling purposes of the building.

Despite the decrease in demand for nonrenewable primary energy by the use of adsorption cooling systems is supplied by solar energy, such installations are still quite expensive. For the proposed solution, cost of purchase and installation with the launch of the cooling system is about 40865 EUR. This cost is relatively high for a standard medium-sized single-family building with a floor area of $140 \mathrm{~m}^{2}$. In comparison to conventional solutions using the compressor units supplied electrically, with adequate cooling capacity and adequate air flow, the cost of purchase and installation does not exceed EUR 2885.

Such a significant difference in the cost of investment makes it unprofitable. However, the adsorption cooling system supplied by the solar energy can also generate heat for heating and hot water preparation. That possibility gives the work as a heat pump with lower heat source in the form of solar collectors. The only requirement to use such a system of heating and cooling is its work on low parameters for heating (i.e., radiant heating system or air heating system). In the proposed solution, an air heating system using an existing installation of air distribution is used. This solution reduces the costs associated with the installation of radiators and piping of a traditional central heating system.

To verify the viability of the investment, an analysis of costs associated with the implementation and operation of adsorption cooling systems supplied by solar collectors (with hot water heating function 
and low temperature heating system) corresponding to the traditional solution of using the compressor cooling unit, condenser hot water tank, and central heating system with radiators supplied by a gas boiler has been carried out.

Based on the analysis, it was found that the simple payback time SPBT in ASCH was 19.3 years. It is assumed that the reduction of costs is associated with traditional installations (e.g., central heating, hot water), which would have been incurred without the use of ASCH. In the traditional system, at least one boiler replacement should be assumed during that period of time. Therefore a simple payback period will be reduced. Due to its high availability and low risk of failure, the ASCH provides a 20-year time period without making an additional financial cost.

The ecological effect implies the better use of the potential of solar energy, reducing significantly the demand for nonrenewable primary energy for cooling purposes of the building. Analysing two ways to provide and process the energy for the final consumer, the environmental effect of the proposed solution can be demonstrated.

In a traditional solution (described in Section 2.1) using compressor cooling unit, condenser hot water tank, and central heating system with radiators supplied by a gas boiler, energy is processed with the use of primary energy in an amount of 45.2 units to heat production, 35.5 units to cold production, and 19.3 units to hot water purposes.

In the ASCH supplied by solar collectors (with function of hot water heating and low parameters of heating system), energy is processed with the use of primary energy in an amount of 19.3 units to heat production, 9.9 units to cold production, and 4.8 units to hot water purposes, reducing the maximum demand for nonrenewable primary energy by about $66 \%$ compared to the standard solution, as shown in Fig. 5 (moving down the line of total demand of nonrenewable primary energy). This is mainly due to a significant increase in the potential of solar energy utilisation.

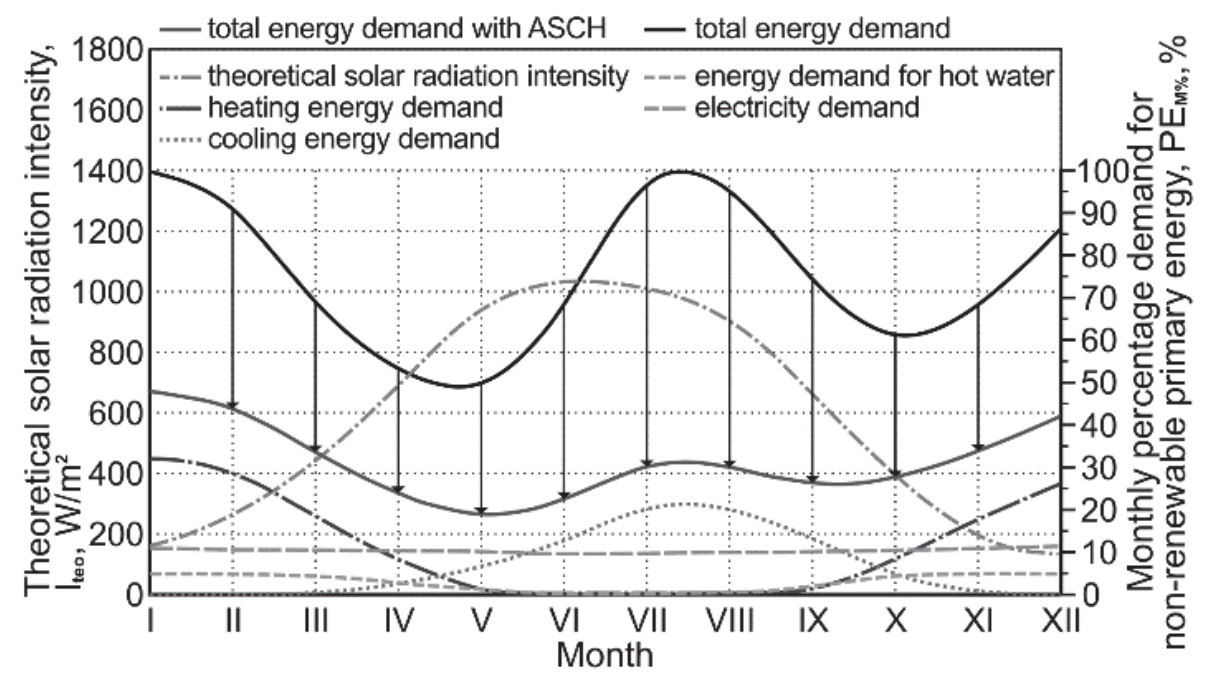

Fig. 5. Theoretical solar radiation intensity and monthly percentage demand for nonrenewable primary energy for a low-energy building supplied by ASCH

\section{CONCLUSIONS}

Conceptual ASCH supplied by solar collectors meets the requirements for reduction of nonrenewable primary energy demand for energy-efficient buildings, although the payback time of investment costs is still quite long (approx. 19 years). However, the conducted studies show other advantages of ASCH. 
A proper selection of heat and cold storage tanks could decrease the power of an additional heat source of ASCH. It is possible to completely omit cold storage by using ASCH with lower efficiency. The need for such an action may occur due to economic reasons or dimensions of the room.

By using solar energy for cooling purposes, problems caused by the variability of solar radiation intensity can be avoided. The use of ASCH supplied by solar collectors increases the potential of solar energy utilisation and leads to a significant reduction in the demand for nonrenewable primary energy for cooling purposes of the building.

The use of ASCH supplied by solar energy as an alternative to compressor cooling unit, absolutely respecting the nonrenewable primary energy, is the ecological solution. The use of using the ASCH supplied by solar energy reduced pollution emissions by about half compared with traditional solutions, and the maximum reduction in the demand for nonrenewable primary energy amounted to about $66 \%$.

Cooling using adsorption processes, unlike compressor cooling units, is not destructive to the ozone layer and does not cause the greenhouse effect, because in these processes agents such as chlorofluorocarbons (CFCs) and hydrochlorofluorocarbons (HCFCs) are not used.

The material has been prepared in terms of Czestochowa University of Technology statutory research $B S / P B-407-302 / 11$.

\section{SYMBOLS}

\begin{tabular}{|c|c|}
\hline$A C$ & adsorption chiller \\
\hline$A S C H$ & adsorption system of cooling and heating \\
\hline COP & coefficient of performance, - \\
\hline$P E_{M \%}$ & monthly percentage primary energy demand, $\%$ \\
\hline$I$ & solar radiation intensity, $\mathrm{W} / \mathrm{m}^{2}$ \\
\hline$Q$ & thermal power, $\mathrm{W}$ \\
\hline$t$ & temperature, ${ }^{\circ} \mathrm{C}$ \\
\hline \multicolumn{2}{|c|}{ Greek symbols } \\
\hline$\tau$ & time, $\min$ \\
\hline \multicolumn{2}{|c|}{ Subscripts } \\
\hline$c$ & coldness \\
\hline$e v$ & evaporator \\
\hline$h$ & heat \\
\hline lhs & lower heat source \\
\hline tech & amount of usable heat produced form solar energ \\
\hline teo & theoretical \\
\hline 0 & initial \\
\hline
\end{tabular}

\section{REFERENCES}

Abreu-Harbich L., Labaki L., Matzarakis A., 2014. Thermal bioclimate as a factor in urban and architectural planning in tropical climates - The case of Campinas, Brazil. Urban Ecosyst., 17, 489-500. DOI: 10.1007/s11252-013-0339-7.

Aristov Y., Glaznev I., Girnik I., 2012a. Optimization of adsorption dynamics in adsorptive chillers: Loose grains configuration. Energy, 46, 484-492. DOI: 10.1016/j.energy.2012.08.001. 
Aristov Y., Sapienz A., Ovoshchnikov D., Freni A., Restuccia G., 2012b. Reallocation of adsorption and desorption times for optimisation of cooling cycles. Int. J. Refrig., 35, 525-531. DOI: 10.1016/j.ijrefrig.2010.07.019.

Askalany A., Salem M., Ismael I., Ali A., Morsy M., Saha B., 2013. An overview on adsorption pairs for cooling. Renew. Sustain. Energy Rev., 19, 565-572. DOI: 10.1016/j.rser.2012.11.037.

Carutasiu M., Ionescu C., Necula H., 2016. The influence of genetic algorithm parameters over the efficiency of the energy consumption estimation in a low-energy building. Energy Procedia, 85, 99-108. DOI: 10.1016/j.egypro.2015.12.279.

Cholewa T., Rosiński M., Spik Z., Dudzińska M., Siuta-Olcha A., 2013. On the heat transfer coefficients between heated/cooled radiant floor and room. Energy Build., 66, 599-606. DOI: 10.1016/j.enbuild.2013.07.065.

Cholewa T., Siuta-Olcha A., Skwarczyński M., 2011. Experimental evaluation of three heating systems commonly used in the residential sector. Energy Build., 43, 2140-2144. DOI: 10.1016/j.enbuild.2011.04.026.

Chou D., Chang C., Chang J., 2016. Energy conservation using solar collectors integrated with building louver shading devices. App. Therm. Eng., 93, 1282-1294. DOI: 10.1016/j.applthermaleng.2015.09.014.

Eshraghi J., Narjabadifam N., Mirkhani N., Sadoughi Khosroshahi S., Ashjaee M., 2014. A comprehensive feasibility study of applying solar energy to design a zero energy building for a typical home in Tehran. Energy Build., 72, 329-339. DOI: 10.1016/j.enbuild.2014.01.001.

Facao J., Lobato A., Baldo C., 2014. The coolsun triple-technology approach to reach high solar fractions for space heating, space cooling and domestic hot water. Energy Procedia, 48, 554-560. DOI: 10.1016/j.egypro.2014.02.065.

Freni A., Sapienza A., Glaznev I., Aristov Y., Restuccia G., 2012. Experimental testing of a lab-scale adsorption chiller using a novel selective water sorbent "silica modified by calcium nitrate". Int. J. Refrig., 35, 518-524. DOI: 10.1016/j.ijrefrig.2010.05.015.

Gargari C., Bibbiani C., Fantozzi F., Campiotti C., 2016. Simulation of the thermal behavior of a building retroffited with a green roof: optimization of energy efficiency with reference to Italian climatic zones. Agric. Agric. Sci. Procedia, 8, 628-636. DOI: 10.1016/j.aaspro.2016.02.085.

Hassan H., Mohamad A., 2012. A review on solar-powered closed physisorption cooling systems. Renew. Sustain. Energy Rev., 16, 2516-2538. DOI: 10.1016/j.rser.2012.02.068.

Hassan H., Mohamad A., Al-Ansary A., 2012. Development of a continuously operating solar-driven adsorption cooling system: Thermodynamic analysis and parametric study. Appl. Therm. Eng., 48, 332-341. DOI: 10.1016/j.applthermaleng.2012.04.040.

Jazizadeh F., Ghahramani A., Becerik-Gerber B., Kichkaylo T., Orosz M., 2014. Human-building interaction framework for personalized thermal comfort-driven systems in office buildings. J. Comput. Civil Eng., 28, 2-16. DOI: 10.1061/(asce)cp.1943-5487.0000300.

Jribi S., Saha B., Koyama S., Chakraborty A., Choon Ng K., 2013. Study on activated carbon/HFO-1234ze(E) based adsorption cooling cycle. Appl. Therm. Eng., 50, 1570-1575. DOI: 10.1016/j.applthermaleng.2011.11.066.

La D., Dai Y., Li H., Li Y., Kiplagat J, Wang R., 2011. Experimental investigation and theoretical analysis of solar heating and humidification system with desiccant rotor. Energy Build., 43, 1113-1122. DOI: 10.1016/j.enbuild.2010.08.006.

Li H., Dai Y., Köhler M., Wang R., 2013. Simulation and parameter analysis of a two-stage desiccant cooing/heating system driven by solar air collectors. Energy Convers. Manage., 67, 309-317. DOI: 10.1016/j.enconman.2012.11.005.

Lu Z., Wang R., Xia Z., Lu X., Yang C., Mac Y., Ma G., 2013a. Study of a novel solar adsorption cooling system and a solar absorption cooling system with new CPC collectors. Renew. Energy, 50, 299-306. DOI: 10.1016/j.renene.2012.07.001.

Lu Z., Wang R., Xia Z., 2013b. Experimental analysis of an adsorption air conditioning with micro-porous silica gel-water. Appl. Therm. Eng., 50, 1015-1020. DOI: 10.1016/j.applthermaleng.2012.07.041.

Myat A., Choon N., Thu K., Kim Y., 2013. Experimental investigation on the optimal performance of Zeolitewater adsorption chiller. Appl. Energy, 102, 582-590. DOI: 10.1016/j.apenergy.2012.08.005.

Palm J., Reindl K, 2016. Understanding energy efficiency in Swedish residential building renovation: A practice theory approach. Energy Res. Social Sci., 11, 247-255. DOI: 10.1016/j.erss.2015.11.006.

Rezk A., Al-Dadah R., 2012. Physical and operating conditions effects on silicagel/water adsorption chiller performance. Appl. Energy, 89, 142-149. DOI: 10.1016/j.apenergy.2010.11.021. 
Sapienza A., Glaznev I., Santamaria S., Freni A., Aristov Y., 2012. Adsorption chilling driven by low temperature heat: New adsorbent and cycle optimization. Appl. Therm. Eng., 32, 141-146. DOI: 10.1016/j.applthermaleng.2011.09.014.

Sarbu I., Sebarchievici C., 2013. Review of solar refrigeration and cooling systems. Energy Build., 67, $286-297$. DOI: $10.1016 /$ j.enbuild.2013.08.022.

Schicktanz M., Hu P., Henninger S., 2012. Evaluation of methanol/activated carbons for thermally driven chillers, part II: The energy balance model. Int. J. Refrig., 35, 554-561. DOI: 10.1016/j.ijrefrig.2011.03.014.

Sekret R., Turski M., 2012. Research on an adsorption cooling system supplied by solar energy. Energy Build., 51, 15-20. DOI: 10.1016/j.enbuild.2012.04.008.

shop.powerauditing.com/c25,cooling-systems. Gabriel Miczka Przedsiębiorstwo. Retrived April 7, 2015.

Solmus I, Kaftanoglu B, Yamal C, Baker D., 2011. Experimental investigation of a natural zeolite-water adsorption cooling unit. Appl. Energy, 88, 4206-4213. DOI: 10.1016/j.apenergy.2011.04.057.

SorTechAG. Retrived April 7, 2015 from www. sortech.de.

Szargut J., 2010. Energy of exergy. Rynek Energii, 5, 3-5.

Szargut J., Stanek W., 2010. Thermo-climatic cost of the domestic consumption products. Energy, 35, 1196-1199. DOI: 10.1016/j.energy.2009.04.025.

Szyc M., Nowak W., 2014. Operation of an adsorption chiller in different cycle time conditions. Chem. Process Eng., 35, 109-119. DOI: 10.2478/cpe-2014-0008.

Tso C., Chao C., Fu S., 2012. Performance analysis of a waste heat driven activated carbon based composite adsorbent - Water adsorption chiller using simulation model. Int. J. Heat Mass Transf., 55, 7596-7610. DOI: 10.1016/j.ijheatmasstransfer.2012.07.064.

Vasta S., Freni A., Sapienza A., Costa F., Restuccia G., 2012. Development and lab-test of a mobile adsorption air-conditioner. Int. J. Refrig., 35, 701-708. DOI: 10.1016/j.ijrefrig.2011.03.013.

Wawrzyńczak D., Nowak W., 2009. Application of low parameter PSA process for capture of $\mathrm{CO}_{2}$ from flue gases emitted during oxygen-enriched combustion. Chem. Process Eng., 30, 589-602.

Wojdyga K., An investigation into the heat consumption in a low-energy building. Renew. Energy, 34, 29352939. DOI: 10.1016/j.renene.2009.04.001.

Zhang X., Song B., Bai Q., Yang C., 2013. Performance analysis on a new type of solar air conditioning system. Energy Build., 60, 280-285. DOI: 10.1016/j.enbuild.2013.01.018.

Received 13 April 2015

Received in revised form 27 April 2016

Accepted 27 April 2016 